\title{
Nineteen-year retrospective evaluation of pemphigus in a single dermatology centre in Istanbul, Turkey
}

\author{
${ }^{1}$ Departments of Dermatology, Kafkas University, Kars, Turkey \\ ${ }^{2}$ Departments of Dermatology, Istanbul Medeniyet University, Istanbul, Turkey \\ ${ }^{3}$ Department of Dermatology, Haseki Training and Research Hospital, Istanbul, Turkey \\ ${ }^{4}$ Departments of Dermatology, Duzce University, Duzce, Turkey
}

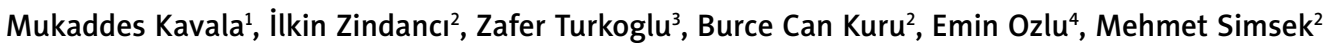

Adv Dermatol Allergol 2020; XXXVII (1): 23-28 DOI: https://doi.org/10.5114/ada.2020.93380

\begin{abstract}
Introduction: Pemphigus is an autoimmune intra-epidermal bullous disease of the skin and mucosae. Aim: To retrospectively evaluate the course, prognosis and clinical features of pemphigus.

Material and methods: The files of 196 pemphigus patients admitted to our clinic between December 1995 and December 2014 were collected and analysed.

Results: The male to female ratio among patients was $1: 1.88$. Pemphigus vulgaris (PV) was the most common clinical variant observed in 175 (89.3\%) of the patients, followed by pemphigus foliaceus (PF) in 14 (7.1\%) of the patients. The mean patient age at disease onset was 50 years. PV presented itself as skin lesions in 55 (31.4\%) of the patients and as oral mucosa lesions in 120 (68.6\%) of the patients. Complete remission and treatment withdrawal were obtained in $112(57.1 \%)$ of the patients, for a mean period of $2.91 \pm 2.66$ years (range: 4 months to 13 years). The mortality rate was $6 \%$, and relapse occurred in $16(14.3 \%)$ of the patients for a mean relapse period of $2.15 \pm 1.88$ years (range: 6 months to 7 years). Mucocutaneous pemphigus (MCP) was the major clinical pattern observed in 96 (49\%) of the patients.

Conclusions: Within our study population, pemphigus predominately affected females, and the most common clinical variant was PV, a subtype that frequently occurs in middle-aged individuals. MCP was the most common clinical pattern. Although MCP and higher doses of corticosteroids were needed to control pemphigus, they did not seem to influence the prognosis.
\end{abstract}

Key words: pemphigus, treatment, mortality.

\section{Introduction}

Pemphigus is a blistering autoimmune disease of the skin and mucous membranes. It is mediated by autoantibodies that bind to the keratinocyte surface antigens: desmoglein (Dsg) 1 and 3, and it results in acantholysis and the formation of epidermal blisters. Several epidemiologic studies and various types of surveys have investigated pemphigus in several countries around the world. Among pemphigus variants, pemphigus vulgaris (PV) is the most common clinical subtype. According to one study, PV in Turkey predominantly affects middle-aged females [1].

\footnotetext{
Aim

The present study was aimed to retrospectively evaluate previous pemphigus cases that were seen at
}

Goztepe Training and Research Hospital Department of Dermatology outpatient clinic. This hospital has been in the Anatolian part of Istanbul for 19 years. The primary reason that dermatology patients residing in the Anatolian part of Istanbul present to our hospital is the treatment and follow-up care that is provided there.

\section{Material and methods}

Data from the files of all 196 patients who had been diagnosed with pemphigus and were admitted to our dermatology clinic between December 1995 and December 2014 were examined and analysed. Each patient file contained the following data: age, sex, relapses, treatment, follow-up care, clinical presentation, clinical variants of pemphigus, presence of associated diseases, initial lesions and their evolution, the season during which the onset of

Address for correspondence: Assist. Prof. Emin Ozlu MD, Department of Dermatology, Duzce University, 81200 Duzce, Turkey, phone: +90 (505) 2788174, fax: +90 380 5421387, e-mail: dermatologg@gmail.com Received: 14.05.2018, accepted: 30.07.2018. 
pemphigus began and the time-lag between the onset of pemphigus and the diagnosis of the disease. The diagnosis of pemphigus was confirmed by histological and direct and indirect immunofluorescent criteria. The body was divided into 8 surface areas: scalp, face/neck, upper half of the trunk, lower half of the trunk, upper limbs, lower limbs, oral mucosa and genital region. Each case was scored as mild, moderate or severe according to the number of involved areas (mild: $\leq 3$, moderate: 4-6, severe: $\geq 7$ ) [2]. All patients were treated primarily with 1-1.5 mg/kg/day of prednisone (40-120 mg/ day) combined with azathioprine (100-150 mg/day), which was dosed according to the severity of the disease. Only patients who experienced side effects from azathioprine received mycophenolate sodium (1,440 mg/day) or dapsone (100-150 mg/day) as steroid-sparing agents. In addition to their treatments, patients who did not respond to standard immunosuppressive combination regimens, as well as those who showed relapses after cessation of systemic therapy, were treated with intravenous immunoglobulin $(2 \mathrm{~g} / \mathrm{kg}$ percycle, over 5 days, every 4 weeks), or rituximab (2 1,000 mg infusions 15 days apart). Treatment was aimed at achieving a negative direct immunofluorescence (DIF) finding in patients with no skin lesions. After beginning their treatment, each patient received clinical and immunological follow-up care (using indirect immunofluorescence) every third or fourth week and every sixth month. DIF tests were performed on patients who showed negative indirect immunofluorescence (IIF) results. Patients with no lesions and with negative DIF findings had their medications discontinued.

\section{Statistical analysis}

Data analysis was performed using the statistical program - Number Cruncher Statistical System (NCSS) 2007 and Power Analysis and Sample Size (PASS) 2008 Statistical Software (Utah, USA). The Kruskal-Wallis test, Mann-Whitney $U$ test and Pearson $\chi^{2}$ test were used to compare the study results. $P<0.05$ was considered to be statistically significant.

\section{Results}

\section{Patient characteristics}

One hundred and ninety-six patients with pemphigus were studied. With a male to female ratio of $1: 1.88$, 68 (34.7\%) of the patients were male, and 128 (65.3\%) of the patients were female (Table 1$)$. The mean age at the onset of disease was $51.15 \pm 14.60$ years (range: 17-91 years old,). Three patients were within their second decade of life (range: 17-18 years old). One hundred and twenty-seven (64.8\%) of the patients were $41-70$ years old, $53(27.0 \%)$ of the patients were older than 71 and 16 (8.2\%) of the patients were younger than 40. Based on the established clinical pattern, mucosal pemphigus (MP), cutaneous pemphigus (CP) and mucocutaneous pemphigus (MCP) were observed in 54 (27.5\%), 46 (23.5\%) and 96 (49\%) of the patients, respectively. A statistically significant association was found between the ages of the patients and their clinical patterns. The mean age of patients with CP was significantly higher than that of patients with MCP $(p<0.05)$ (Table 2). The lag time between the onset of pemphigus and its diagnosis was shorter than 6 months for 135 (68.9\%) of the patients, 6-12 months in $44(22.4 \%)$ of the patients and was longer than 12 months for 17 (8.7\%) of the patients. No significant association was found between diagnostic lag time and clinical pattern $(p>0.05)$ (Table 2). The mean lag times between onset of disease and diagnosis were 6.07 \pm 5.35 months for PV, $7.32 \pm 6.07$ months for pemphigus foliaceus (PF), $12.04 \pm 10.44$ months for pemphigus herpetiformis (PH) and $9.50 \pm 3.53$ months for paraneoplastic pemphigus (PNP). Fifty-one (26.0\%) patients experienced the first signs of the disease in spring, 60 (30.6\%) patients experienced the first signs of the disease in summer, 33 (16.8\%) patients experienced the first signs of the disease in autumn, and 52 (26.5\%) in winter. Only $3(1.5 \%)$ patients had a family history of pemphigus.

Table 1. Clinical variants of pemphigus with respect to age and sex

\begin{tabular}{|c|c|c|c|c|c|c|c|c|}
\hline \multirow{2}{*}{$\begin{array}{l}\text { Clinical } \\
\text { variants of } \\
\text { the disease }\end{array}$} & \multicolumn{4}{|c|}{ Sex distribution } & \multicolumn{4}{|c|}{ Age at onset (mean) } \\
\hline & Male (\%) & Female (\%) & $M: F$ & Total (\%) & Male & Female & Total & Range \\
\hline PV & $60(30.6)$ & $115(58.7)$ & $1: 1.92$ & $175(89.3)$ & 51 & 50 & 50 & $17-91$ \\
\hline $\mathrm{PF}$ & $6(3.1)$ & $8(4.1)$ & $1: 1.33$ & $14(7.1)$ & 55 & 65 & 61 & $47-85$ \\
\hline $\mathrm{PH}$ & - & $3(1.5)$ & - & $3(1.5)$ & - & 57 & 57 & $48-66$ \\
\hline PNP & - & $2(1.0)$ & - & $2(1.0)$ & - & 40 & 40 & $28-53$ \\
\hline $\mathrm{PE}$ & $1(0.5)$ & - & - & $1(0.5)$ & 47 & - & 47 & - \\
\hline PVg & $1(0.5)$ & - & - & $1(0.5)$ & 54 & - & 54 & - \\
\hline $\begin{array}{l}\text { Total } \\
\text { pemphigus }\end{array}$ & $68(34.7)$ & $128(65.3)$ & $1: 1.88$ & $196(100)$ & 51 & 51 & 51 & $17-91$ \\
\hline
\end{tabular}

PV-pemphigus vulgaris, PF-pemphigus foliaceus, $P V g$ - pemphigus vegetans, $P E-$ pemphigus erythematosus, $P H$ - pemphigus herpetiformis, $P N P$ - paraneoplastic pemphigus. 
Table 2. Evaluation of pemphigus patients with respect to the clinical pattern

\begin{tabular}{|c|c|c|c|c|c|}
\hline Parameter & $N$ & $\mathrm{CP}$ & MP & MCP & $P$-value \\
\hline$N(\%)$ & 196 & $46(23.5)$ & $54(27.5)$ & 96 (49.0) & \\
\hline Sex: & 196 & & & & b0.109 \\
\hline Male & 68 & $18(39.1)$ & $14(25.9)$ & $36(37.5)$ & \\
\hline Female & 128 & $28(60.9)$ & $40(74.1)$ & $60(62.5)$ & \\
\hline Age, mean \pm SD [years] & 196 & $56.63 \pm 14.11$ & $51.94 \pm 15.76$ & $48.08 \pm 13.42$ & ${ }^{\text {aa } 0.004^{\star *}}$ \\
\hline $\begin{array}{l}\text { Lag time between onset and diagnosis, } \\
\text { mean } \pm \text { SD [months] }\end{array}$ & 196 & $6.39 \pm 5.46(5)$ & $6.49 \pm 5.96(5)$ & $6.14 \pm 5.27(4.25)$ & a0.980 \\
\hline Treatment period, mean \pm SD [years] & 112 & $2.92 \pm 3.25(1.63)$ & $2.66 \pm 2.22(2.0)$ & $3.11 \pm 2.70(2.0)$ & ${ }^{\mathrm{a}} 0.584$ \\
\hline Dosages of prednisone, mean \pm SD [mg] & 112 & $74.91 \pm 24.41(70)$ & $77.58 \pm 22.43(80)$ & $101.63 \pm 17.24(100)$ & ${ }^{\mathrm{a}} 0.001^{\star *}$ \\
\hline Relapse, $n$ (\%): & 112 & & & & b0.073 \\
\hline$(-)$ & 96 & $20(83.3)$ & $30(76.9)$ & $46(93.9)$ & \\
\hline$(+)$ & 16 & $4(16.7)$ & $9(23.1)$ & $3(6.1)$ & \\
\hline $\begin{array}{l}\text { Lag time between remission and relapse, } \\
\text { mean } \pm \text { SD [years] }\end{array}$ & 16 & $1.75 \pm 0.64(1.75)$ & $2.73 \pm 1.55(2.50)$ & $2.83 \pm 3.61(1.0)$ & ${ }^{\mathrm{a}} 0.493$ \\
\hline Mortality, $n$ (\%): & 150 & & & & ${ }^{c} 0.099$ \\
\hline$(-)$ & 141 & 31 (91.2) & $46(100)$ & 64 (91.4) & \\
\hline$(+)$ & 9 & $3(8.8)$ & 0 & $6(8.6)$ & \\
\hline
\end{tabular}

${ }^{a a}$ Oneway Anova test, ${ }^{a}$ Kruskal Wallis test, ${ }^{b}$ Pearson $\chi^{2}$ test, ${ }^{c}$ Fisher Freeman Halton test. ${ }^{*} P<0.05,{ }^{* *} p<0.01$.

\section{Clinical variants}

PV was the major clinical variant of the disease observed in 175 (89.3\%) patients, followed by PF in 14 (7.1\%) patients, $\mathrm{PH}$ in $3(1.5 \%)$ patients, PNP in 2 (1.0\%) patients, pemphigus erythematosus (PE) in $1(0.5 \%)$ patient and pemphigus vegetans (PVg) in $1(0.5 \%)$ patient (Table 1$)$. The PV to PF ratio was $12.5: 1$. No cases of drug-induced or IgA pemphigus were noted.

\section{Sex and age distribution}

The PV subset was composed of 60 men and 115 women, with a male-to-female ratio of $1: 1.92$ (Table 1). The mean age of female subjects was $49.90 \pm 15.15$ years old, and the mean age of the male subjects was 51.42 \pm 13.96 years old. The mean age for the onset of PV was $50.42 \pm 14.73$ years old, and the mean age for the onset of PF was $60.71 \pm 11.03$ years old. The mean age of onset for PF was significantly higher than it was for PV $(p<0.05)$.

\section{Initial lesions and their evolution}

PV manifested as oral mucosa lesions in 120 (68.6\%) of the patients and later spread to the skin of 69 (39.4\%) of the patients. For the remaining 51 (29.2\%) of the patients, the oral cavity was the only affected area. In 55 (31.4\%) of the patients, skin lesions were the only presenting sign, and in 27 (15.4\%) of the patients, the oral cavity was later affected. In the remaining 28 (16.0\%) patients, the skin was the only affected area. The skin was the only affected area in patients with PF, PH and PE. In patients with PNP and PVg, lesions were seen in the oral mucosa before spreading to the skin.

\section{Results of treatment and clinical follow-up}

A total of 150 (76.5\%) patients were evaluated, but 46 (23.5\%) patients were lost at follow-up. Nine (6\%) patients died (1 PH patient and $8 \mathrm{PV}$ patients) due to sepsis, pneumonia or cardiovascular complications during their treatments. The mean age of death was $59.05 \pm 17.54$ years old (range: 31-91 years old). Complete remission and treatment withdrawal was obtained in 112 (57.1\%) of the patients studied, with average prednisone dosages of $87.53 \pm 24.11 \mathrm{mg} /$ day, combined with an adjuvant drug for a mean of $2.91 \pm 2.66$ years (range: 4 months to 13 years). Twenty-nine (19.3\%) of the patients are still under active or maintenance treatment. Twenty-four patients received mycophenolate sodium as a steroid-sparing agent, and 21 patients received dapsone as a steroid-sparing agent. Nineteen patients received intravenous immunoglobulin (IVIg) combined with either azathioprine or mycophenolate sodium. One patient was controlled with a combination of IVIg, rituximab, prednisone and azathioprine. In 99 of the patients with PV, an average prednisone dosage of $89.83 \pm 22.49 \mathrm{mg} /$ day, combined with an adjuvant drug, was administered until complete remission and treatment withdrawal for an average period of $2.97 \pm 2.69$ years. Conversely, 9 of the patients with PF received an average prednisone dosage of $56.66 \pm 18.70 \mathrm{mg} /$ day, combined with an adjuvant drug, for an average period of 1.66 \pm 0.87 years. Data collected from 112 patients, including 
Table 3. Treatment results of 112 patients who had complete remission

\begin{tabular}{lcc}
\hline Treatment & & $\boldsymbol{N}(\%)$ \\
\hline Dose of prednisone [mg] & $40-60$ & $11(9.8)$ \\
\cline { 2 - 3 } & $60-80$ & $20(17.9)$ \\
\cline { 2 - 3 } & $80-120$ & $81(72.3)$ \\
\hline Treatment & $\leq 1$ & $30(26.8)$ \\
\cline { 2 - 3 } & $1.1-3$ & $50(44.6)$ \\
\cline { 2 - 3 } & $>3$ & $32(28.6)$ \\
\hline Reliod [years] & $(-)$ & $96(85.7)$ \\
\hline Lag time between & $(+)$ & $16(14.3)$ \\
remission and relapse & $\leq 1$ & $3(18.8)$ \\
\cline { 2 - 3 } [years] & $2-3$ & $9(56.3)$ \\
\hline
\end{tabular}

data on relapses, treatment periods, dosages of prednisone and lag times between remissions and relapses of the disease, are shown in Table 3. A significant association was found between the dosage of prednisone and the clinical pattern. Prednisone dosages for patients with MCP were significantly higher than those for patients with MP and CP $(p<0.05)$. However, there was no significant association between the treatment period and clinical pattern for any variant of pemphigus ( $p>0.05$ ) (Table 2). Relapses occurred in 16 (14.3\%) patients for a mean relapse period of $2.15 \pm 1.88$ years (range: 6 months to 7 years). No significant associations were found between rates of relapse or mortality and clinical pattern $(p>0.05)$ (Table 2). There were also no associations among relapse, treatment periods or dosages of prednisone $(p>0.05)$ (Table 4).

\section{Associated diseases}

The most significant associated previous or concurrent diseases were autoimmune thyroid diseases (9 patients Hashimoto's thyroiditis, 1 patient - Graves' disease), papillary thyroid carcinoma (1 patient), hepatitis B and C infection (1 patient each), renal parenchymal disease (3 patients), myeloproliferative disease (1 patient), pancreas and parotid carcinoma (1 patient each) and idiopathic thrombocytopenic purpura (1 patient). One case of PNP was associated with thymoma, and another was associated with Castleman disease. One case of each of the following skin diseases associated with pemphigus occurred: vitiligo, psoriasis, Kaposi sarcoma and discoid lupus erythematosus.

\section{Discussion}

With a male to female ratio of $1: 1.88$, our study revealed that pemphigus is predominant in females. Similar findings have been reported by authors from Iran, Italy, Kuwait, Turkey, Tunisia, Croatia and South Africa [1, 3-8].

Although the onset of pemphigus ranged from 17-91 years of age, $64.8 \%$ of the patients were $41-70$ years old.
Table 4. Dose of prednisone and treatment period with respect to relapse

\begin{tabular}{|c|c|c|c|c|}
\hline Variable & $N$ & $\begin{array}{l}\text { Relapse (+) } \\
\quad(n=16)\end{array}$ & $\begin{array}{l}\text { Relapse (-) } \\
(n=96)\end{array}$ & $P$-value \\
\hline $\begin{array}{l}\text { Treatment period, } \\
\text { mean } \pm \text { SD [years] }\end{array}$ & 112 & $\begin{array}{c}2.15 \pm 1.88 \\
\quad(1.58)\end{array}$ & $\begin{array}{c}3.04 \pm 2.76 \\
(2.0)\end{array}$ & ${ }^{\mathrm{a}} 0.172$ \\
\hline $\begin{array}{l}\text { Dose of } \\
\text { prednisone, } \\
\text { mean } \pm \text { SD [mg] }\end{array}$ & 112 & $\begin{array}{c}85.50 \pm 24.95 \\
(100)\end{array}$ & $\begin{array}{c}87.87 \\
\pm 24.08 \\
(100)\end{array}$ & ${ }^{\mathrm{a}} 0.752$ \\
\hline
\end{tabular}

The mean age of onset was 50 years, a relatively high age of onset in comparison to the data collected from Iran, Turkey, Tunisia, South Africa and Saudi Arabia [1, 3, 4, 8, 9] but consistent with data collected in Italy and Croatia $[5,6]$. In our group, the mean age for patients with PF was 60 years, and the mean age for patients with PV was 50 years. Although these data differ greatly from reports encountered in Kuwait and Tunisia, where the mean age of onset for PF was smaller, it is comparable to the data collected in another Turkish study [1, 7, 8]. The 6-month lag time between the onset and diagnosis of PV was shorter for our patients than it was for those in southern Turkey [1]. This might be explained by the fact that patients in southern Turkey seek medical services later than patients who seek care at our hospital.

In $56.6 \%$ of our patients, the first signs of pemphigus occurred during the spring and summer months. We hypothesised that higher rates of first signs of pemphigus in spring and summer may be associated with higher air temperature and ultraviolet exposure. This finding was corroborated by reports of reductions in the onset of pemphigus during the winter months $[10,11]$.

Familial types of pemphigus are rare and were observed in only $1.5 \%$ of the study's patients. These findings are consistent with the data collected from Iran [3].

The most common subtype of pemphigus is PV [1]. Uzun et al. [1] evaluated epidemiological features of pemphigus in the Mediterranean region of Turkey. In this study, $P V$ was the most common clinical variant of the disease with a high PV to PF ratio of $12.5: 1$ [1]. In another study conducted by Bozdag et al. [12], the epidemiology of pemphigus in the western region of Turkey was evaluated. In this study, $93.1 \%$ of the patients had PV and $54 \%$ of the patients had both mucosal and skin involvement at the onset of the disease. Although these results are also comparable to those found in reports from Iran, Italy, Israel, Croatia and Bulgaria, they are dissimilar to results found in Finland, where PE is prevalent, and in Mali, Tunisia and South Africa, where PF is prevalent [3-6, 8, 10, 13-15].

At the onset of the disease, PV was localised in the oral cavities of $68.6 \%$ of our patients. This information correlates with Iranian and Kuwaiti reports that 57-84.3\% of PV cases began with localised forms of the disease in the oral cavity $[7,16]$. For the majority of our patients, the 
disease then spread to the skin. PV remained confined to only oral mucosae (29.2\% of our patients), a relatively high figure in comparison to the data collected from Iran and Turkey [1, 3]. Patients with PF had lesions localised to the skin with no oral involvement. Similar results were reported in data collected from Kuwait and South Africa $[4,7]$. MCP was the major clinical pattern of the disease observed in $49 \%$ of our patients. In support of data collected from Iran and Kuwait, there were no significant differences in the disease between genders $[3,7,16]$. Our patients with CP were older than those with MCP, a finding that had not been mentioned anywhere in the existing literature. The dosages of prednisone used in patients with MCP were higher than those used in patients with MP and CP, which is in agreement with a report of MCP having a poor response to therapy [16]. However, there were no significant differences between treatment periods with respect to the clinical pattern. This information differs from reports of patients with mucosal lesions responding to therapy more slowly than patients with skin lesions [17].

The association of pemphigus with another immune diseases, viral infections and neoplasias has been reported in the literature [18]. Recently, pemphigus has been described to be associated with autoimmune thyroid diseases. It has been shown that anti-TPO autoantibodies positivity is higher in pemphigus patients than in the control group [19]. In our previous study, we found significantly higher antithyroid antibodies (anti-TPO, anti-Tg) positivity in pemphigus patients (9\%) when compared to the control group (1.2\%) [20]. In our study, thyroid disease was the most common concurrent disease and it was observed in a previous study from Turkey [1]. We hypothesise that higher frequency of autoimmune thyroid diseases in pemphigus patients may be associated with the autoimmune origin of the diseases.

Fifty-seven percent of our patients had complete remissions and were able to discontinue their treatments. This figure is relatively high when compared to data collected from Iran and Turkey $[1,3,16]$. Our study's mortality rate of $6 \%$ was comparable to the mortality rates of 4.8-6.2\% observed in previous studies [1, 3]. In contrast to a study suggesting that patients who suffered from skin and mucosal involvement had higher mortality rates than patients who suffered solely from involvement of the skin, we noticed no significant difference between mortality rates with respect to the clinical pattern [21].

Of the patients with no skin lesions and negative DIF results, $14.3 \%$ had relapses during a mean follow-up period of $2.15 \pm 1.88$ years. These figures are consistent with previous reports that DIF is unhelpful in predicting relapses of pemphigus [2]. Today, it is suggested that the detection of Dsg 1 and Dsg 3 proteins should be used to assess disease severity and response to therapy [22, 23]. In our study, we were unable to demonstrate IgG antibodies to Dsg 1 and 3 via enzyme-linked immunosorbent assay (ELISA), and immunofluorescence studies were used to monitor disease activity.

In our group, no association was found between relapse rates and clinical patterns. These data differ from a study that found higher rates of relapse in MCP patients during the follow-up period [16]. We also observed that the treatment period and the dosages of corticosteroids did not seem to influence relapse rates.

Viral infections, including Herpes simplex virus 1 and 2 (HSV1/2), cytomegalovirus (CMV), Epstein-Barr virus, and Dengue virus have been suggested to trigger or exacerbate pemphigus [24]. The role of genetic factors in the pathogenesis of pemphigus have been broadly studied. An association between HLA class II alleles and PF, PV or both has been demonstrated in different ethnic groups [25]. In our previous study, circulating pemphigus autoantibodies were detected in $26.7 \%$ of the relatives of pemphigus patients and in only two of the controls by indirect immunofluorescence staining $(p=0.0001)$ [26]. In another study, we found that HLA-A28 and B44 positivity was specific to the Turkish population and had a role in susceptibility to disease [27]. However, we could not evaluate viral serology and HLA subtypes due to the laboratory technical limitations in our study.

\section{Conclusions}

The results of our study demonstrated that PV was the most common clinical variant of pemphigus in the Anatolian part of Istanbul and it predominantly occurred in middle-aged females. MCP was the most common clinical pattern. Although higher dosages of corticosteroids are required to control MCP, the clinical pattern does not seem to influence the prognosis of pemphigus. Further epidemiological investigations including HLA analysis are needed because of heterogeneous population composed of different ethnic groups in this region.

\section{Acknowledgments}

Mukaddes Kavala and Ilkin Zindancı contributed equally to this manuscript.

\section{Conflict of interest}

The authors declare no conflict of interest.

\section{References}

1. Uzun S, Durdu M, Akman A, et al. Pemphigus in the Mediterranean region of Turkey: a study of 148 cases. Int I Dermatol 2006; 45: 523-8.

2. Kavala M, Altıntas S, Kocaturk E, et al. Ear, nose and throat involvement in patients with pemphigus vulgaris: correlation with severity, phenotype and disease activity. J Eur Acad Dermatol Venereol 2011; 25: 1324-7. 
3. Chams-Davatchi C, Valikhani M, Daneshpazhooh M, et al. Pemphigus: a analysis of 1209 cases. Int J Dermatol 2004; 44: 470-6.

4. Aboobaker J, Morar N, Ramidal PK, et al. Pemphigus in South Africa. Int J Dermatol 2001; 40: 115-9.

5. Micali G, Musumeci ML, Nasca MR. Epidemiologic analysis and clinical course of 84 consecutive cases of pemphigus in eastern Sicily. Int J Dermatol 1998; 37: 197-200.

6. Ljubojevic S, Lipozencic J, Brenner S, et al. Pemphigus vulgaris: a review of treatment over a 19-year-period. J Eur Acad Dermatol Venereal 2002; 16: 599-603.

7. Alsaleh QA, Nanda A, Al-Baghli NM, et al. Pemphigus in Kuwait. Int J Dermatol 1999; 38: 351-6.

8. Bastuji-Garin S, Souissi R, Blum L, et al. Comparative epidemiology of pemphigus in Tunisia and France: unusual incidence of pemphigus foliaceus in young Tunisian women. J Invest Dermatol 1995; 104: 302-5.

9. Tallab T, Joharji H, Bahamdan K, et al. The incidence of pemphigus in the southern region of Saudi Arabia. Int I Dermato 2001; 40: 570-2.

10. Tsankov N, Vassileva S, Kamarashev J. Epidemiology of pemphigus in Sofia, Bulgaria. A 16-year retrospective study. Int J Dermatol 2000; 39: 104-8.

11. Wilson C, Wojnarowska F, Mehra NK, et al. Pemphigus in Oxford, UK, and New Delhi, India: a comparative study of disease characteristics and HLA antigens. Dermatology 1994; 189: 108-10.

12. Bozdag K, Bilgin i. Epidemiology of pemphigus in the western region of Turkey: retrospective analysis of 87 patients. Cutan Ocul Toxicol 2012; 31: 280-5.

13. Pisanti S, Sharav Y, Kaufman E, et al. Pemphigus vulgaris: incidence in Jews of different ethnic groups, according to age, sex, and initial lesion. Oral Surg Oral Med Oral Pathol 1974; 38: 382-7.

14. Mahé A, Flageul B, Cissé I, Pemphigus in Mali: a study of 30 cases. Br J Dermatol 1996; 134: 114-9.

15. Hietanen J, Salo OP. Pemphigus: an epidemiological study of patients treated in Finnish hospitals between 1969 and 1978. Acta Derm Venereol 1982; 62: 491-6.

16. Kavusi S, Daneshpazhooh M, Farahani F, et al. Outcome of pemphigus vulgaris. J Eur Acad Dermatol Venereol 2008; 22: 580-4.

17. Seidenbaum M, David M, Sandbank M. The course and prognosis of pemphigus. A review of 115 patients. Int I Dermato 1988; 27: 580-4.

18. Ruocco E, Wolf R, Ruocco V, Brunetti G, Romano F, Schiavo AL. Pemphigus: associations and management guidelines: facts and controversies. Clin Dermatol 2013; 31: 382-90.

19. Baldini E, Odorisio T, Tuccilli C, et al. Thyroid diseases and skin autoimmunity. Rev Endocr Metab Disord 2018; 19: 311-23.

20. Kavala M, Kural E, Kocaturk E, et al. The evaluation of thyroid diseases in patients with pemphigus vulgaris. Sci World J 2012; 2012: 146897.

21. Wolf R, Landau M, Tur E, Brenner S. Early treatment of pemphigus does not improve the prognosis. A review of $53 \mathrm{pa}-$ tients. J Eur Acad Dermatol Venereol 1995; 4: 131-6.

22. Fortina $A B$, Faggion D, Pigozzi $B$, et al. Detection of auotoantibodies againist recombinant Desmoglein 1 and 3 molecules in patients with pemphigus vulgaris: corelation with disease extent at the time of diagnosis and during followup. Clin Dev Immunol 2009; 2009: 187864.
23. Kwon EJ, Yamagami J, Nishikawa T, Amagai M. Anti-desmoglein IgG autoantibodies in patients with pemphigus in remission. J Eur Acad Dermatol Venereol 2008; 22: 1070-5.

24. Machado AR, La Serra L, Turatti A, et al. Herpes simplex virus 1 and cytomegalovirus are associated with pemphigus vulgaris but not with pemphigus foliaceus disease. Exp Dermatol 2017; 26: 966-8.

25. Brochado MJ, Nascimento DF, Campos W, et al. Differential HLA class I and class II associations in pemphigus foliaceus and pemphigus vulgaris patients from a prevalent Southeastern Brazilian region. J Autoimmun 2016; 72: 19-24.

26. Kavala M, Kocaturk OE, Demirkesen C, et al. Detection of pemphigus autoantibodies in healthy relatives of Turkish patients with pemphigus. Indian J Dermatol Venereol Leprol 2007; 73: 240-2.

27. Kavala M, Can B, Diler S, et al. HLA haplotypes in Turkish patients with pemphigus and their healthy relatives. Turk Derm 2007; 41: 86-9 